\title{
The Role of Human Resource System in Developing a Culture of Innovation
}

\author{
Dr. Fawaz Ali Thawabieh \\ Modern College for Science and Business, Oman
}

\begin{abstract}
The Research aims on Human Resource Management and innovation has to date relied on a theoretical assumption that there exists an identifiable set of HR practices which organizations seeking to be innovative should adopt. However, analysis of the various prescriptions of HR practices for innovation reveals a high level of internal inconsistency, leading to conflicting advice for practitioners. Furthermore, a review of empirical research on the topic indicates that HR practices within innovative organizations are remarkably similar to those found in the best practice literature This raises questions about the link between strategy and HRM, and about the theoretical foundations of research on HRM and innovation. Drawing on recent research on HRM and firm performance, I suggest that research on HRM and innovation can benefit from incorporating elements from both contingency theory and best practice approaches into the existing configuration theory approach. A change in direction for both theoretical and empirical research on HRM and innovation is proposed. This paper is laid out as follows. In part one, I ask what a strategy of innovation is, and consider what employee behaviors are believed to be consistent with such a strategy. The second section compares and contrasts different authors' prescriptions of HR practices for innovation, and also compares the findings of research on HRM and innovation with the findings of the best practice approach. In the final part I consider the implications of MY review for future research on this topic. I propose a broadening of the theoretical base on which research on HRM and innovation is founded, and discuss the particular challenges involved in conducting empirical research on HR systems for innovation.

Keywords: Human Resource Management; It can be said that it is a set of functions and activities used by institutions, whether public or private to improve productivity in their work efficiently and effectively. Researcher Dr. Fawaz A. Thawabieh, 2019 Innovation: is 'the intended introduction and implementation within a job, work team or organization of ideas, processes, products or procedures which are new to that job, work team or organization and which are designed to benefit the job, the work team or the organization.' (West and Farr, 1990).
\end{abstract}

(4) (1) CC BY: Creative Commons Attribution License 4.0

\section{Introduction}

The organizations around the globe donate best need to innovations, as this leads them in becoming successful over long period of time, (Chen and Huang, 2009).

What type of HR system is most appropriate for a firm wishing to pursue a strategy of innovation? This question has attracted attention from researchers since the early 1980s. In fact, it can be argued that this stream of research predated by as much as a decade a much wider interest in the links between HRM and organizational performance; Interest in the topic of innovation is also growing rapidly. Global dissemination of information via technology has ensured that competitive advantage based on a particular product or process is no longer sustainable. In the information age, sustainable competitive advantage belongs to those firms who continually reinvent themselves at a pace which is consistent with the rapid pace of change in the environment. The result is that the pressure on firms to innovate in order to survive is greater than ever before. These parallel developments in HRM research and the broader business environment ensure that both academic and practitioner interest in the topic of HR systems for innovation is likely to grow. The question of how research on this topic should proceed is therefore an important one, and is the subject of this paper.

\section{Theoretical Underpinnings of Research on HRM and Innovation}

Firm-level research in HRM generally reflects three different theoretical perspectives - the Best Practice view, the Best Fit or configuration-based view, and contingency approaches. The Best Practice view posits the existence of clusters or bundles of High Performing Work Practices which can enhance the performance of all firms which adopt them ${ }^{1}$. For example, Pfeffer (1994) recommends fourteen best HR practices for adoption by all firms, including selectivity in recruitment, high wages, incentive pay, employee ownership and promotion from within (Pfeffer, 1994). The Best Fit or configuration theory approach proposes that firm strategy is the critical factor which should be considered in deciding which system of HR practices a firm should adopt ${ }^{3}$. For example, Miles and Snow (1984) identify three unique clusters of HR practices which they propose fit best with Prospector, Defender or Analyzer strategies respectively (Miles and Snow, 1984). Finally, contingency theorists argue that a variety of internal and external environmental influences combine to determine the optimal mix of HR practices for any particular firm. A large number of the contingencies which have attracted research attention, including strategy, firm size, firm age, local labour markets and union coverage (internal) and industry complexity and munificence (external) (Huselid and Rau, 1997). 
Theory and research on HRM and innovation has to date been firmly rooted in the configuration approach. This theoretical perspective suggests that there is an identifiable "strategy of innovation" which some firms adopt in pursuit of competitive advantage, an oft-cited example is the "prospector" type described by Miles and Snow (1984). Research on HRM and innovation is based on the idea that there is a unique cluster of HR practices which is most appropriate for firms pursuing a strategy of innovation (Schuler and Jackson, 1987); the underlying premise is that the adoption of these HR practices will enable any "innovative" firm to outperform innovative rivals who do not adopt them. However, the latter notion remains untested in the empirical literature on HRM and innovation. Rather, empirical studies have focused on testing whether the sets of "HR practices for innovation" rooted in prescriptive research have generally been adopted by firms pursuing a strategy of innovation.

The logic of the theory underlying research on HRM and innovation provides us with two specific criteria against which we can assess the progress of research on this topic. First, the theory suggests there is a single set of HR practices which will elicit employee behaviors which are consistent with a strategy of innovation. Second, if the theory makes sense, this cluster of practices should be in some sense unique; in other words, they must be identifiably different from HR practices associated with alternative strategies. This paper undertakes an analysis of research on HRM and innovation and assesses the progress which has been made using the above criteria as a yardstick. In particular, I compare different prescriptions of HR systems for innovation to assess whether there is a consensus among researchers about the HR practices which innovative firms should adopt. Contrary to what the theory would lead one to expect, I find that the prescriptions of HR practices for innovation are rife with internal inconsistencies and contradictions. Empirical research on the topic has identified HR practices which have been adopted by firms pursuing a strategy of innovation. I compare these practices with research from the "Best Practice" literature to assess progress against the second criterion which is, whether these "HR practices for innovation" are in some sense unique. Remarkably, I find that almost all of the HR practices for innovation have also been identified as generic "Best HR practices", a finding which presents a further challenge to the theoretical underpinnings of research on HR systems for innovation.

\subsection{What is a Strategy of Innovation?}

Due to the speed of changes occurring within certain organizational environments as a result of globalize competition and rapid technological developments, organizations are faced with challenges never encountered before. When pursuing a strategy of innovation, organizations attempt to embrace these challenges through the adoption or development of new products, services, operations or practices.

\subsection{Defining Innovation}

Despite the fact that there are many descriptions of innovation within the literature, there is still a lack of consensus on a single definition of the concept. Nevertheless many useful definitions and typologies of innovation have been provided, adding to MY understanding of the concept. West and Farr define innovation as: the intentional introduction and application within a role, group or organization of ideas, processes, products or procedures, new to the relevant unit of adoption, designed to significantly benefit the individual, the group, the organization or wider society (West and Farr, 1990).

This would suggest that innovative organizations are problem finders, actively focusing on existing customer or market problems on the one hand, and existing practices and procedures on the other, and then generating ideas aimed at improving or solving these problems through the development or adoption of new products, services and procedures.

However, one threat to MY understanding of the concept concerns the use of the terms creativity and entrepreneurship somewhat synonymously with innovation. Some studies have viewed entrepreneurship as a multidimensional construct used to describe organizations in terms of their innovativeness, proactiveness and their willingness to take risks (Miller, 1983). This would suggest that innovation is only one attribute, although an essential one, of the entrepreneurial organization. The distinction between creativity and innovation may be one of emphasis rather than one of category, where creativity is concerned (Morris and Jones, 1993). with bringing ideas into existence, while innovation is concerned with implementing these ideas. For the purposes of the present paper, strategies of innovation and entrepreneurship will be viewed synonymously, while creativity will be viewed as a desirable attribute of individuals within the innovative organization (Morris et al., 2010).

\subsection{Different Types of Innovations}

Three of the most widely cited typologies distinguish between specific innovations in terms of whether they are technical or administrative, whether they are concerned with products or processes, or whether they can be described as radical or incremental. Damanpour (1991), provides useful descriptions of each of these types of innovations. Technical innovations refer to products and services, and also production processes and operations and relate to the technical core of the organization, while administrative innovations are more directly related to management and concern changes in organizational structures or administrative activities, and therefore pertain to the administrative core of the organization. Product innovations concern the introduction of new products or services to meet the customers needs, while process innovations are introduced to production or service operations and may include new materials, equipment or task specifications. Radical innovations are described as non-routine and represent a departure from existing practices, operations, processes and technologies, whereas incremental innovations are more routine, representing smaller departures from existing procedures. 


\subsection{Strategic Typologies}

Configuration theory suggests that organizations can be described in terms of strategic types, where their degree of innovativeness depends on their positioning along a strategic continuum (Mintzberg, 1978). At one end of the continuum are defender organizations which operate in narrow product and market domains, where the focus is on continuity and reliability and where fundamental changes are rarely made. Such organizations tend to be characterized by both gradual and cautious growth, paying relatively little attention to other organizations, or events and trends occurring within the external environment. At the other extreme, prospector organizations operate in broad product and market domains, constantly seeking opportunities in an environment characterized by change and uncertainty. They constantly strive to identify emerging trends in their environment so that innovation can be sustained, compromising internal efficiency if necessary.

In order for organizations to achieve competitive advantage, they must adopt one of three generic strategies. firms with a specific strategic orientation should outperform those who are "stuck in the middle" and identifies strategies of cost leadership, differentiation or focus. Strategies of cost leadership aim to provide lower costs to customers relative to competitors, while focus strategies target a specific market segment or develop particular product lines. Firms pursuing differentiation strategies emphasize innovation and strive to offer something new or unique to customers in terms of their products and services (Porter, 1985).

Adopting Porters typology, Schuler \& Jackson describe the possible HR implications for organizations pursuing strategies of cost reduction, innovation and quality enhancement. However, they emphasize that although these strategies may be presented as distinct types some overlap can occur, and various parts of a firm may pursue one or more strategy simultaneously (Schuler, 1987).

\subsection{Cultural Aspects of Innovation}

Innovative organizations need to adopt a "culture of pride and climate of success". In addition, the structures within such organizations must be compatible with the culture and argues that bureaucratic structures can stifle innovation. She terms non-innovative organizations as segmentalist, where the structure makes it difficult to solve problems through the development of innovative solutions since problems are broken up and assigned to various subunits, with each subunit having only one piece of the problem to solve (Kanter, 1983). On the other hand, innovative organizations adopt an integrative approach where sub problems are aggregated into larger problems allowing greater insight into the appropriate action required. Therefore, reduced layers in the hierarchy, greater lateral communication, and greater empowerment to those at lower levels are favorable characteristics of the innovative organization.

Tushman and O'Reilly (1997), view culture as one of the most important factors in the management of innovation and emphasize the need for flexibility, speed and responsiveness in adapting to changing circumstances on the one hand, while on the other they suggest that some degree of consistency, reliability and stability should be maintained. Therefore, within the innovative organization a more participative management style is favored, where communication and teamwork are of paramount importance. In addition new ideas and risk taking behaviors among employees should be encouraged where mistakes and possible failures are tolerated, particularly if employees are acting in the interests of the customer. Therefore, drawing from the definition provided by West and Farr (1990) I suggest that a strategy of innovation requires an organization to be revolutionary, assertive and proactive, where the primary focus is on implementing new ideas concerning products, services, practices or operations, whether initiated or adopted. Through constant monitoring of their environments they systematically seek opportunities to exploit, anticipating and responding to situations before they have to. In order to foster a culture for innovation, they have flexible structures, empowered employees, and encourage risk taking, while accepting mistakes and occasional failure.

\subsection{Innovative Behaviors and Skills}

Research linking competitive strategies and HR practices adopts a behavioral perspective (Miles and Snow, 1984; Schuler, 1987). The logic is that since different firm strategies require different behaviors from employees, the HR system must not only ensure that employees have the necessary skills but must also motivate the appropriate behaviors. This requires some consensus about what key employee behaviors are considered consistent with a Strategy of innovation (Cappelli and Singh, 1992).

Employee skills which have been associated with innovative behaviour include problem solving and communication skills. Amabile's componential model of creativity identifies "domain-relevant skills" and "creativity-relevant skills" as two necessary attributes for individual creativity on any given task. Attributes within these domains include an awareness of the feasibility of implementing innovations, familiarity with the relevant markets and a cognitive style which favors taking a new perspective to problems (Amabile, 1983).

Since there is a high level of consensus about the types of employee skills and behaviors appropriate for a strategy of innovation, it might be reasonable to expect a similar degree of consensus about the type of HR system which firms seeking to pursue a strategy of innovation should adopt. However, as I shall see in the next section, this is far from being the case. 


\section{Review and Analysis of Research on HRM and Innovation 3.1. Structure of the Employment Relationship}

The decision on whether to hire from the market at all levels of the organization or limit points of entry and promote from within is one of the most basic HR issues faced by organizations. To a large extent, a firm's approach to this question significantly determines the nature of the employment relationship and the psychological contract which underpins it. Even more importantly for the argument presented here, the structure of the employment relationship influences firms' choice of HR practices by imposing constraints on the choices available to them (Doeringer and Poire, 1971). Reflecting its fundamental importance, researchers on HRM and innovation have directly addressed the question of what employment relationship structure should be adopted by firms wishing to pursue a strategy of innovation.

Unfortunately, the level of internal inconsistency in the prescriptive literature on HRM and innovation is nowhere more evident than in the treatment of this most basic HR question.

Innovating organizations need to do much of their recruitment externally, to try to retain a fit between their human resource pool and the changing needs of the organization. Innovative organizations are characterized as operating in environments which are both unstable and ambiguous, thereby making work role and behaviour requirements more difficult to define (Delery and Doty, 1996). For example, Miles and Snow (1984) suggest that prospector organizations are more concerned with sophisticated external recruitment practices at all levels of the organization than either defender or analyzer organizations (Miles and Snow, 1984). On the other hand, Schuler and Jackson (1987) present a case which is almost diametrically the opposite of the above (Schuler and Jackson, 1987).

They argue that because innovative organizations require risk taking behaviour and tolerance of inevitable failures, job security should be provided and a long-term orientation encouraged. They therefore prescribe the use of entry level recruitment combined with extensive training and job security.

The implications of these two different approaches to structuring the employment relationship are significant. Configuration theory, on which research on HRM and innovation, posits a single, internally consistent system of HR practices consistent with a strategy of innovation. As I illustrate below, the HR practices which flow from these two approaches are very different, and for the most part are mutually exclusive. I will revisit the important issue of the relationship between the structure of the employment relationship and a strategy of innovation when I review empirical research later in this section, and again when I discuss future research directions in Section III.

\subsection{Recruitment and Selection}

A surprisingly small amount of prescriptive attention has been devoted to specifying the methods of recruitment and selection of employees which should be adopted by organizations pursuing a strategy of innovation. The advice which is offered is fairly general in nature. For instance, more general, implicit and less formalized selection criteria are proposed by some authors (Olian and Rynes, 1984). It is also argued that recruitment systems which are more open will allow employees to select themselves into innovative positions, allowing a better match between the requirements of the organization and the individual needs of the employee (Morris and Jones, 1993; Schuler and Jackson, 1987). Miles and Snow, while advocating the acquisition of human resources rather than internal development, offer little specific advice on how this should be done, apart from suggesting the use of some psychological testing ${ }^{24}$. While Schuler and Jackson specify desirable employee behaviors associated with a strategy of innovation, they offer little advice on how this should be incorporated into the recruitment and selection process (Schuler, 1987).

\subsection{Socialization}

Socialization involves immersing the individual in the culture and practices of the organizations, where they become aware of the norms, values and attitudes which are consistent with the organization and it's strategy. It is suggested that such practices help to forge a psychological commitment by the individual to the organization and perhaps encourage employee behaviors which are less predictable (Schuler and Jackson, 1987). A number of authors emphasize the particular importance of extensive socialization and orientation programs for new employees in innovative organizations (Tushman and O'Reilly, 1997). In fact, this is one of the few HR practices for innovation concerning which there would appear to be a high level of consensus in the literature.

\subsection{Training}

The encouragement of creative and experimental behaviour not only requires the necessary skills and confidence on the part of the individual, but also a long term training and development strategy by the Organization (Tidd et al., 1997). Training activities in innovative organizations should be spontaneous, informal, and unsystematic and should encourage high employee participation (Schuler and Jackson, 1987). Similarly, Schafer argues that in order to fit with the constantly changing environment and variable job requirements, the training provided should be continuous, less structured and should focus on individualized knowledge requirements. This should enable employees to adapt to these changing conditions, to respond in unique ways to new challenges, and to become more comfortable with ambiguity (Schafer, 1990).

HR practices which are believed to facilitate innovative behaviors such as co-operation and interdependence take a long term approach and include the use of extensive training and development activities, and interdepartmental transfers ${ }^{31}$. In innovative organizations, intensive training should be provided where employees develop a broad range of skills which can then be used in other parts of the organization. However, an entirely 
different view is offered by Delery and Doty who suggest that innovative organizations provide only a small amount of informal training Delery and Doty (1996), and Sonnenfield and Peiperl (1988) who argue that due to the portability of skills, very little training, usually on-the-job, should be provided by such organizations. In general, these conflicting prescriptions for training are consistent with the fundamentally different approaches to structuring the employment relationship reviewed above.

\subsection{Development/Careers}

While the structure of the employment relationship at least partially predetermines how organizations approach employee development and careers issues, there are a number of interesting issues raised in the treatment of these issues in the literature. Schuler argues that broad career paths which develop employees based on implicit rather than specific criteria are more adaptable to changing circumstances, and therefore allow employees to be moved around the organization and be developed more broadly. Furthermore, since it is more difficult to promote individuals through traditional methods in innovative organizations, establishing several ladders enlarges the opportunities for employees to advance (Schuler and Jackson, 1987). Careers can thus be redefined in terms of skill growth and crossfunctional movement in order to overcome reduced opportunities for upward mobility.

Highly skilled employees may be attracted to innovative organizations since they provide greater opportunities for advancement into a variety of different positions. Schuler suggests that although recruiting internally or "promoting from within" can serve as an effective reward for good performance, it generally commits the organization to providing training and career development to high performers (Schuler and Jackson, 1987).

\subsection{Performance Appraisal}

Performance appraisals which communicate a tolerance for failure and which provide employment security are believed to influence employee motivation in innovating organizations. Appraisals which reflect the long term, emphasize results, and assess group rather than individual achievements are most likely to have these effects (Schuler and Jackson, 1987). performance appraisals should be based on individual achievements, should focus on behaviors rather than results, and should be used for developmental purposes, rather than evaluative purposes (Youndt et al., 1996).

\subsection{Compensation Systems}

Some authors suggest that compensation systems should emphasize individual skills (Dyer \& Holder; Delery \& Doty) while Youndt et al. suggest that group-based incentives should also be provided. Jackson \& Schuler argue that organizations pursuing a strategy of innovation should place less emphasis on results-based bonuses or incentives, which would penalize employees for engaging in risk-taking behaviors (Schuler, 1987).

While some authors also argue that innovating organizations should adopt compensation systems which emphasize external or market based equity (Arthur, 1994; Miles and Snow, 1984; Schuler, 1987; Youndt et al., 1996) argue that internal equity should be emphasized. These emphases reflect the general approach to the employment relationship adopted by these authors. They suggest that basic pay rates can be low but employees should have the opportunity to become stockholders and have a greater say over the mix of components in their pay. Dyer and Holder (1988), lend further support for this argument for greater flexibility in pay systems..

\subsection{Contradictions and Deadly Combinations}

In order to provide support for the underlying theory, the prescriptive and empirical research reviewed on HRM and innovation should ideally yield a single set of "best HR practices for innovative organizations". Indeed, some interpretations seem to suggest that this is the case (Morris and Jones, 1993)

\subsection{Empirical Evidence Concerning HR Practices and Innovation}

My analysis to this point has focused on the prescriptive literature on HRM and innovation. While many of these prescriptions were based on "empirical" case study research, the approach was one of theory building rather than theory testing. In this section I briefly review empirical studies which have attempted to test these prescriptions by comparing them with practices adopted by innovative organizations. I consider the issues in the same general order as the treatment of prescriptive research above.

Support for a link between innovative strategies and the use of HR practices which offer job security has been reported by Peck (1994) and other authors (Morris and Jones, 1993).

Peck found that prospector organizations were more rather than less likely to use the internal labour market to develop skills. Similarly, Delery and Doty (1996) found that prospector banks who made greater use of internal career opportunities had higher returns than did defender banks.

Morris and Jones (1993), found that innovative organizations tended to place greater emphasis on extensive socialization of new employees. They also found that while training and development programs in innovative organizations were continuous or ongoing, they were also systematic and planned. Innovative firms also used programs which encouraged high employee participation, which were group-focused and which assumed a longer term perspective. Innovative organizations tended to provide more training overall, focusing on skills for both present and for possible future roles. With regard to careers, Morris and Jones (1993) found that innovating organizations were more likely to have selection and staffing procedures designed around multiple career paths. 
The findings by Peck (1994) and Delery and Doty (1996) in relation to the greater use of internal recruitment would suggest that innovating organizations tend to emphasize promotion from within.

On performance appraisal, empirical research suggests that innovative organizations are more likely to use results-oriented performance appraisals (Morris and Jones, 1993). Delery and Doty (1996), found that banks pursuing a strategy of innovation benefited more from results-oriented appraisals than did banks pursuing a defender strategy. Research also suggests that innovative organizations are more likely to use results from performance appraisals for evaluative purposes rather than for longer term development (Olian and Rynes, 1984). Innovative organizations tended to use performance appraisals with a longer term focus, with greater employee participation and explicit encouragement of risk-taking behaviors (Morris and Jones, 1993).

Compensation practices in innovating organizations were more likely to include bonuses and incentives which were based on long term performance and which emphasized individual rather than group-based achievements (Morris and Jones, 1993). In addition, compensation practices tended to place greater emphasis on job security rather than higher pay. There is no significant association between compensation systems and a strategy of innovation (Peck, 1994).

\subsection{HR Practices for Innovation or Just Best Practices}

My second criterion for assessing whether research on HRM and innovation offers support for its theoretical foundations is that HR practices for a strategy of innovation should be different from HR practices for other strategies. One way to assess this is to compare the findings of empirical research on HRM and innovation with the empirical findings of the "best practice" approach to firm-level HRM research. Directly challenging the notion that the "fit" between strategy and HR practices is critical, the best practice approach to HRM takes the view that the adoption of a specific set of Best HR Practices enhances firm performance regardless of strategic orientation (Pfeffer, 1994).

All of the HR practices for innovation which have received empirical support are also proposed as elements of High Performing Work Systems, also known as Best HR Practices. This suggests that the Best HR practices for innovation may not, in fact, be strategy specific but are simply good HR practices for any organization whatever their strategy. Against this second criterion, then, the research on HRM and innovation does not appear to offer support for the theoretical foundations on which it is based.

\section{New Directions for Research on HR Systems for Innovation}

The analysis in the foregoing section illustrates that the configuration theory approach to research on HRM and innovation has yielded ambiguous research findings as well as advice for practitioners which is at best confusing and at worst dysfunctional. In this section I consider the direction that both theoretical and empirical research on this topic should now take. On theory, I propose integrating elements of the two other theoretical approaches found in firm level research in HRM -- contingency theory and best practice -- into the theoretical base for research in this domain. I argue that this broader approach can resolve many of the internal inconsistencies found in MY literature review and provide the foundation for further productive research on this topic. For empirical research, I review major measurement issues faced by researchers on HR systems for innovation, and consider some ways of tackling them.

\subsection{Theory Issues}

The literature on HRM and innovation reflects a strongly voluntarily view of the role of management. That is, it relies on the assumption that management are not only able to choose the strategy they wish to pursue, but they are then able to change all aspects of the employment relationship to align the HR system with that strategy. Prospector organizations should in general adopt a "Market type system", while defender organizations are best suited by an "Internal system" (Delery and Doty, 1996). However, both organizational research and common sense suggest that the employment system to be found in any organization at any point in time is primarily a function of the history and culture of the organization as well as the institutional environment in which it operates (Cappelli and Crocker-Hefter, 1996). The degree to which management can change the employment system is thus severely constrained not just by these factors, but also by more tangible factors such as union agreements or the need to provide particular incentives to attract and retain employees in particular labour markets.

I therefore suggest that research on HRM and innovation has relied on assumptions about managerial discretion which may only apply in startup operations and greenfield sites, if they apply at all. This research would, I argue, benefit from a more deterministic approach which recognizes the reality that at least some aspects of the employment system in established organizations are characteristics of the organizations rather than HR tools at the discretion of management. For example, I suggested earlier in this paper that the emphasis on provision of employment security is not for the most part a discretionary HR practice. If this fundamental aspect of the employment system is predetermined, then the choices faced by management with respect to other aspects of the employment system are severely constrained.

- A move to a more deterministic ontology will change the basic research question to be tackled by researchers on HRM and innovation. Rather than asking "what type of HR system is most appropriate for a firm wishing to pursue a strategy of innovation?", I suggest a more fruitful agenda can be identified by asking the following:

- What discretionary HR practices are consistent with a strategy of innovation? 
This approach if adopted could retain much of the parsimony of the configuration approach while taking realistic account of the constraints within which firms must operate. Thus, we could avoid the patently inappropriate prescriptions of organic organizational structures for organizations for whom this is clearly not an option.

In basic theory terms, I am suggesting that elements of contingency theory be integrated with the configuration "model" which has been driving research on HRM and innovation. The challenge in moving toward a contingency approach is to optimize the tradeoff between the contingency variables I add to the model (each of which reduces parsimony) and the gains in validity which result. In practical terms, this requires us to suggest how many "types" of employment system should be considered. A dichotomous classification of organizations should be adopted in research on this topic (Damanpour, 1991). A number of authors in HRM have also proposed the existence of two types of employment system, "Internal type system" and the "Market type system". Internal type systems hire mainly from within the organization and offer employees a great deal of employment security, well-defined career ladders, and extensive formal training. By contrast, Market type systems hire almost exclusively from outside the organization, make very little use of internal career ladders, use extensive profit sharing and offer very little employment security (Delery and Doty, 1996).

To illustrate the value of the approach I am suggesting, we considered the implications of a dichotomous classification of organizations into Internal and Market types for the literature reviewed earlier. The following table provides summary descriptions of two proposed systems of HR practices for innovation-- a Market System and an Internal System-- derived form the current literature.

\subsection{Learning from the Best Practice Approach}

My review also indicates that researchers in HRM and innovation need to be more theoretically rigorous when prescribing HR practices for innovation. In particular, the link between proposed HR practices and the desired employee behaviors must be clearly articulated. The Best Practice literature can both inform and complement continued study on the topic of HRM and innovation in this regard. For instance, on a practical level the simple comparison in Table 3 above could be undertaken for all proposed HR practices for innovation. Discovering that a proposed practice is also being researched as a Best Practice may indicate a need for greater specificity about the link to particular innovative behaviors. More efficient use of scarce research resources and greater conceptual clarity in research on HRM and innovation should result.

\subsection{Measurement Issues}

Two major measurement dilemmas emerge from MY review of empirical research on HR systems for innovation. The first concerns whether innovation should be measured in terms of outcomes or as a continual process, where discrete outcomes are assumed to result from the implementation of an overall process or strategy. The second dilemma concerns whether we should study particular HR practices in isolation, or should support for innovation also be measured if HR is assumed to play a role in developing an appropriate culture for innovation? The way in which each of these dilemmas is resolved has significant implications for research on this topic; we therefore address each of these issues separately here.

\subsection{Measuring Innovation / Strategies of innovation}

When I defined innovation in an earlier section, I identified both specific types of innovation (e.g., technical and administrative), and specific types of strategies (e.g., low-cost, quality enhancement and innovation). Accordingly, there are two general approaches to measuring innovation, either in terms of it's outcomes (e.g., number of new products introduced to the market), or in terms of the strategic positioning of a firm (e.g., innovators Vs. low cost providers). Researchers focusing on a particular industry have tended to measure outcomes (Goes and Park, 1987).

In these studies panels of "experts" are used to identify products or services within an industry, and inventories are developed describing both types of innovations. Items are then rated in terms of their innovativeness, and overall innovation is measured in terms of the rate of adoption of these "innovative" products or services within a given period.

The second approach has been applied to studies examining a variety of industries using measurements to assess strategic orientation Dess and Davis (1984) and Shortell and Zajac (1990). These are largely based on strategic typologies, such as Miles and Snow (1984) prospector and defender types, and place organizations along a continuum depending on their degree of innovativeness. Dess and Davis using their own instrument, found support for Porter's generic strategies where for instance, organizations pursuing a strategy of differentiation emphasized variables such as new product development and forecasting of market growth.

Although both approaches are no doubt useful, an interesting question arises concerning the degree to which innovation is actually being measured. For instance, with regard to the first approach, can we assume that the most innovative organizations are those with the highest rate of product innovation, regardless of how successful these innovations have been? Similarly, but in relation to the second approach, are we to assume that organizations are highly innovative because that is how managers within them perceive them to be? Insight on this question might be gained from adopting both approaches sequentially in a single study; i.e., obtaining a measure of strategic orientation initially, and then examining how it is achieved by measuring the specific outcomes of innovation (such as rate of product innovation). For instance, Morris and Jones, in their study included open-ended questions regarding the number of new products or services planned for the following year, and the amount of time devoted to innovation by senior management (Morris and Jones, 1993). It can also be argued that studies which have assumed organizations to 
be innovative based on one of the two measures described above, have disregarded important issues such as whether new ideas and risk taking behaviors are encouraged and whether mistakes are tolerated.

\subsection{HR Practices}

Studies examining HR practices in innovative organizations have relied almost exclusively on the prescriptions of HR practices for innovation provided within the literature. For instance, Peck adopted Miles and Snow's typology of HR practices for both defender and prospector organizations and asked HR managers to rate the extent to which their organization emphasized a "make" or "buy" orientation in their use of HR practices (Peck, 1994). This method is useful in the sense that it allows for the fact that different HR practices may be used within different units or at various levels of the same organization, but that an overall 'make' or 'buy' policy may prevail. However, on the other hand, it may result in 'central' tendencies in responses, where no definite emphasis on either orientation can be properly established. With regard to this issue, perhaps a more favorable measure was that employed by Morris and Jones typology of HR practices for innovative organizations. Similar to Peck, they asked managers to rate the extent to which particular HR practices were emphasized within their organization but they used a bi-polar scale as opposed to obtaining ratings.

A further concern is that measuring HR practices in isolation disregards the fundamental issue of whether or not organizations foster an appropriate climate for innovation. Many studies have failed to identify the source of new ideas and do not consider other factors such as organizational goals, structure, and flexibility and decision making styles. One measure which addresses issues such as these is provided by Siegel and Kaemmerer and assesses support for innovation (Siegel and Kaemmerer, 1978). Clearly, if it is assumed that the use of particular HR practices have a significant role in developing an appropriate culture for innovation, then studies which illuminate the relationship between HR practices, culture and strategy would be most welcome.

\section{Conclusion}

I suggest that the single most important research issue in this domain concerns the nature of the link between HR practices and organizational performance. Despite the growing body of research on HR systems for innovation, the specific relationships between HR systems, strategies of innovation and firm performance have not been addressed. Instead, research has examined whether HR practices in innovative organizations are those prescribed by for instance, Miles and Snow, or Schuler and Jackson. Although this type of research undoubtedly adds value in terms of whether these prescriptions are actually applied in organizational settings, a more fundamental issue concerns whether these practice choices enhance the performance of the organizations which adopt them.

Establishing this HR-performance link has proved to be a major challenge for other firm-level research within SHRM and several studies have addressed this relationship with varying degrees of success. Within the best practice literature for instance, studies have found that use of specific practices, or what are now widely referred to as "High Performance Work Practices" enhances organizational performance. For instance, Huselid ${ }^{65}$ found that extensive recruitment and training procedures, incentive compensation and increased employee involvement were associated with lower levels of turnover, higher productivity and better financial performance. By contrast, the issue of performance has been notable by its absence from the literature reviewed here. Thus, after fifteen years of research on the topic, we have no light to shed on whether the choice of HR system has any bearing on the performance of a firm pursuing a strategy of innovation.

The notion of internal and external "fit" suggests that certain combinations of HR practices - which are internally coherent with each other, and externally aligned with organizational strategy - can lead to superior performance. However, in relation to internal fit, there is no support for the existence of complementarities or synergies of HR practices and firm performance (Huselid, 1995). However, their use of crude measures of complementarities, and the fact that they did not examine HR systems in relation to specific strategies would suggest that perhaps such Complementarities are possible. If this were the case then perhaps aligning these practices with strategy would yield greater effects. Therefore, research is needed to identify whether configurations of HR practices with particular strategies lead to synergistic effects.

With regard to identifying the ideal HR system for innovation, it may be that such a definitive HR system would be too rigid for the innovative organization and it's constantly changing needs, but that a flexible combination of both practices recommended in the best practice literature, and those found to be contingent on a strategy of innovation, may be what such organizations need in order to compete successfully.

\section{References}

Amabile, T. M. (1983). The social psychology of creativity: A componential conceptualization. Journal of Personality and Social Psychology, 45: 357-76. Available: https://www.scirp.org/reference/ReferencesPapers.aspx?ReferenceID=1338950

Arthur, J. B. (1994). Effects of human resource systems on manufacturing performance and turnover. Academy of Management Journal, 37(3): 670-87.

Cappelli, P. and Singh, H. (1992). Integrating strategic human resources and strategic management. In D. Lewin, O.S. Mitchell, \& P. Sherer (Eds.), Research frontiers in industrial relations and human resources. Industrial Relations Research Association: Madison, WI.

Cappelli, P. and Crocker-Hefter, A. (1996). Distinctive human resources are firms' core competencies. Organizational Dynamics, 24(3): 7-22. 
Chen, C. H. and Huang, J. W. (2009). Strategic human resource practices and innovation performance-the mediating role of knowledge management capacity. Journal of Business Research, 62(1): 104-14.

Damanpour, F. (1991). Organizational Innovation : A meta-analysis of effects of determinants and moderators. Academy of Management Journal, 34(3): 555-90.

Delery, J. and Doty, D. H. (1996). Modes of theorizing in strategic human resource management : Tests of universalistic, contingency and configurational performance predictions. Academy of Management Journal, 39(4): 802-35.

Dess, G. G. and Davis, P. S. (1984). Porter's (1980) generic strategies as determinants of strategic group membership and organizational performance. Strategic Management Journal, 27(3): 487-505.

Doeringer, P. and Poire, M. (1971). Internal labour markets and manpower analysis. Lexington, MA : Heath.

Dyer, L. and Holder, J. (1988). A strategic perspective of human resource management. In l. Dyer (ed.) human resource management : Evolving roles and responsibilities. American Society for Personnel Administration/Bureau of National Affairs: Washington, DC.

Goes, J. B. and Park, S. H. (1987). Interorganizational links and innovation : The case of hospital services. Academy of Management Journal, 40(3): 673-96.

Huselid, M. A. (1995). The impact of human resource management practices on turnover, productivity and corporate financial performance. Academy of Management Journal, 38(3): 635-70.

Huselid, M. A. and Rau, B. L. (1997). The determinants of high performance work systems: Cross-sectional and longitudinal analyses. Academy of Management Annual Meetings, Human Resources Management Division: Available: http://www.bhbassociates.com/docs/articles/1997_The Determinatns_of_High.pdf

Kanter, R. M. (1983). The change masters. Simon and Schuster: New York.

Miles, R. H. and Snow, C. C. (1984). Designing strategic human resource systems. Organizational Dynamics, 13(1): 36-52.

Miller, D. (1983). The correlates of entrepreneurship in three types of firms. Management Science, 29(7): 770-91.

Mintzberg, H. (1978). Patterns in strategy formulation. Management Science, 24(9): 934-48.

Morris, M. H. and Jones, F. F. (1993). Human resource management practices and corporate entrepreneurship: An empirical assessment from the USA. The International Journal of Human Resource Management, 4(4): 873-96.

Morris, M. H., Kuratko, D. F. and Covin, J. G. (2010). Cengage learning. 3rd edn: 188.

Olian, J. D. and Rynes, S. L. (1984). Organizational Staffing: Integrating practice with strategy. Industrial Relations, 23(2): 170-83.

Peck, S. R. (1994). Exploring the link between organizational strategy and the employment relationship: the role of human resources policies. Journal of Management Studies, 31(5): 715-36.

Pfeffer, J. (1994). Competitive advantage through people. Harvard Business School Press: Boston, Mass.

Porter, M. E. (1985). Competitive Advantage: Creating and sustaining superior performance. Free Press: New York.

Schafer, D. S. (1990). Level of Entrepreneurship and scanning source usage in very small businesses. Entrepreneurship: Theory and Practice, 15(2): 19-31.

Schuler, R. S. (1987). Human resource management practice choices. In schuler, R.S. And youngblood, S.A. (eds.) readings in personnel and human resource management. 3rd edn: West Publishing: St. Paul, MN

Schuler, R. S. and Jackson, S. E. (1987). Linking competitive strategies with human resource management practices. Academy of Management Executive, 1(3): 209-13.

Shortell, S. and Zajac, E. (1990). Perceptual and archival measures of Miles and Snow's strategic types : a comprehensive assessment of reliability and validity. Academy of Management Journal, 33(4): 817-32.

Siegel, S. and Kaemmerer, W. (1978). Measuring the perceived support for innovation in organizations. Journal of Applied Psychology, 63(5): 553-62.

Sonnenfield, J. A. and Peiperl, M. A. (1988). Staffing policy as a strategic response : a typology of career systems. Academy of Management Review, 13(4): 588-600.

Tidd, J., Bessant, J. and Pavitt, K. C. (1997). Managing Innovation. Wiley and Sons: Chichester.

Tushman, M. L. and O'Reilly, C. A. (1997). Winning through innovation. Harvard Business School Press: Boston, MA.

West, M. and Farr, J. (1990). Innovation at work. In M. West and J. Farr (Eds.) Innovation and creativity at work : Psychological and organizational change strategies. New York : Wiley.

Youndt, M., Snell, D. A., Dean, J. W. and Lepak, D. P. (1996). Human resource management, manufacturing strategy, and firm performance. Academy of Management Journal, 39(4): 836-66. 